\title{
Evaluation with Doppler vascular ultrasound in postoperative endovascular treatment of abdominal aortic aneurysm: a prospective comparative study with angiotomography
}

\author{
Ecografia vascular com Doppler na avaliação pós-operatória \\ do tratamento endovascular de aneurisma da aorta abdominal: \\ estudo prospectivo comparativo com a angiotomografia
}

Graciliano Jose França', Liz Andrea Villela Baroncini', Aguinaldo de Oliveira², Enrique Antônio Vidal², Márcio Miyamotto ${ }^{3}$, Jeferson Freitas Toregeani, Luiz Otávio de Mattos Coelho5 ${ }^{5}$ Jorge Rufino Ribas Timi ${ }^{6}$

\begin{abstract}
Background: Diagnosis of abdominal aortic aneurysm (AAA) is usually incidental, and surgical treatment, when indicated, may be open or endovascular. The drawbacks of computed angiotomography (CTA) and the advantages of Doppler ultrasonography have led to the development of alternative follow-up protocols, comparing the two methods. Objective: To determine validity indices for Doppler ultrasonography and to correlate them with CTA results in a group of patients who had undergone elective endovascular treatment of AAAs. Material and methods: Thirty-three patients were selected. The following three items were evaluated: 1) presence or absence of endoleak; 2) presence of blood flow in the aortoiliac segment; and 3) maximum AAA diameter. Results: For the detection of endoleak, Doppler ultrasonography showed a sensitivity of $54.5 \%$, a specificity of $92.8 \%$, a positive predictive value of $85.7 \%$, a negative predictive value of $92.8 \%$, and an overall accuracy of $76 \%$. For the evaluation of blood flow in the aortoiliac segment, values were 100, 97.8, 80, 97.8, and 98\%, respectively. Maximum AAA diameter was similarly measured by both methods, with statistically significant differences (mean difference: $1.98 \mathrm{~mm}$ ). Pearson's correlation coefficient was 0.97, showing that Doppler ultrasonography and CTA yielded similar results. Conclusion: Doppler ultrasonography showed good validity indices and a moderate correlation with CTA in the postoperative evaluation of patients undergoing endovascular treatment of AAAs.
\end{abstract}

Keywords: aortic aneurysm; tomography; ultrasonography; Doppler.

\section{Resumo}

Contexto: $O$ diagnóstico de aneurisma da aorta abdominal (AAA) em geral ocorre incidentalmente, e o tratamento cirúrgico, quando recomendado, pode ser aberto ou endovascular. Tendo em vista as desvantagens da angiotomografia e as potencialidades da ecografia vascular com Doppler, protocolos de seguimento alternativos incluindo os dois métodos têm sido estudados. Objetivos: Determinar índices de validade para a ecografia vascular com Doppler e sua correlação com a angiotomografia na avaliação pós-operatória de pacientes submetidos ao tratamento endovascular eletivo do AAA. Métodos: Foram avaliados 33 pacientes. Os três itens a seguir foram avaliados: 1) presença ou não de vazamento; 2) fluxo no segmento aorto-ilíaco; e 3) diâmetro máximo do AAA. Resultados: Para a detecção de endoleak, a ecografia vascular com Doppler apresentou sensibilidade de $54,5 \%$, especificidade de $92,8 \%$, valor preditivo positivo de $85,7 \%$, valor preditivo negativo de $92,8 \%$ e acurácia total de $76 \%$. Para a avaliação do fluxo no segmento aorto-ilíaco, os valores foram 100, 97,8, 80, 97,8 e 98\%, respectivamente. Quanto ao diâmetro máximo do AAA, não houve diferença estatisticamente significativa entre os métodos (diferença média de 1,98 mm). O coeficiente de correlação de Pearson foi de 0,97, demonstrando que a ecografia vascular e angiotomografia fornecem resultados semelhantes. Conclusão: A ecografia vascular com Doppler apresenta bons índices de validade e correlação moderada com a angiotomografia na avaliação pós-operatória de pacientes submetidos a tratamento endovascular de AAAs.

Palavras-chave: aneurisma aórtico; tomografia; ultrassonografia; Doppler.

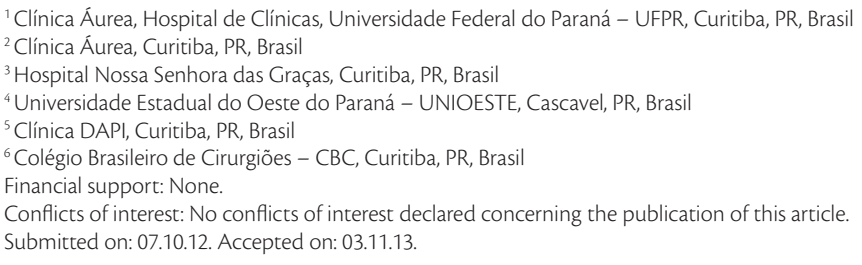

This study was carried out at the vascular ultrasonography units of Clínica Aurea (vascular ultrasound exams) and Clínica de Diagnóstico por Imagem DAPI (computed angiotomography exams), Curitiba, Paraná, Brazil.

This paper is part of a doctoral dissertation presented at the Graduate Program in Surgical Practice at Universidade Federal do Paraná (UFPR). 


\section{INTRODUCTION}

Abdominal aortic aneurysm (AAA) is defined as an enlargement of the aorta by $\geq 50 \%$ of the normal arterial diameter. AAAs are the most frequent type of aneurysm found in clinical practice; they are 3- to 7-fold more frequent than thoracic aortic aneurysms, and affect more men than women, at a 4:1 ratio. AAA rates are higher in elderly white men and lower in blacks, ${ }^{1}$ but in Asia, the frequency is equivalent to that observed in whites. In Brazil, reported prevalence of AAAs in people aged $>60$ years ranges from $2.1^{2}$ to $2.5 \%{ }^{3}$.

The diagnosis of AAA usually occurs incidentally. To reduce the morbidity and mortality associated with eventual rupture (mortality rates range from 65 to $85 \%{ }^{4}$ ), elective treatment is recommended whenever its size reaches $5.5 \mathrm{~cm}$ in diameter. However, subgroups of individuals with low surgical risk and long life expectancy may choose to be treated early. ${ }^{5}$

The first operations performed to correct AAAs, conducted by Dubost in the 1950s, were based on the removal of the entire dilated segment with arterial reconstruction. Some credit Creech, others Javid, and yet others DeBakey, with the idea of just inserting a tube into the aneurysm while keeping the weakened arterial wall surrounded. For several decades, this tube was installed inside the aorta by suture, i.e., opening the aneurysm and then closing it around the tube. Only in the late 1980s did it become possible to introduce the tube through the femoral artery and then fix it within the aneurysm using stents ${ }^{6}$; this process became known as endovascular repair. Now, after over 20 years, endovascular repair has replaced open surgical treatment of AAAs in a large number of cases, but not all.

The choice between open surgery and endovascular repair is still controversial ${ }^{7}$. If a vascular surgeon chooses to treat his AAA patient using endovascular repair, the patient should be followed for life with diagnostic exams, to ensure that the aneurysm is excluded from the blood stream. The main complications are occlusion of the prosthesis or its branches and leakage (endoleak).

Endoleak can be defined as the transmission of flow and pressure into the aneurysm sac. Various protocols have been proposed to diagnose complications of endovascular repair of AAAs, especially endoleak. In almost all cases, the follow-up protocol was based on serial computed angiotomography (CTA) scans, beginning in the first month after repair, then after 6 and 12 months, and yearly thereafter ${ }^{8}$. However, the frequent use of CTA in the public and private health care settings is costly, and the cumulative exposure to radiation may increase the risk of cancer ${ }^{9}$. Also, CTA uses iodinated contrast, which is nephrotoxic and may trigger anaphylatic reactions. For these reasons, alternative follow-up protocols, including Doppler vascular ultrasound, have been studied ${ }^{10}$.

Lacerda ${ }^{11}$ published a study demonstrating comparable results for vascular ultrasound and CTA $(\mathrm{p}=0.8$ for Kappa) in the detection of leak, suggesting that vascular ultrasound is a promising method for the diagnosis and monitoring of potential leaks in patients treated with endovascular surgery. In Brazil, experience with systematic comparisons between the two methods is still limited.

Taking into consideration the disadvantages of CTA and the potential advantages of Doppler vascular ultrasound, this prospective study was designed to compare CTA (considered the gold standard method) and Doppler vascular ultrasound in patients subjected to endovascular treatment of AAAs. The objective of the study was to determine validity indices of Doppler vascular ultrasound and to correlate findings with CTA results in the postoperative evaluation of patients who had undergone elective endovascular treatment of AAAs.

\section{MATERIAL AND METHODS}

A total of 33 patients ( 30 men, $73 \pm 6.9$ years) were evaluated. Fifty Doppler ultrasound and CTA examinations were compared. Each patient underwent one to four comparative exams. Indication criteria for elective endovascular treatment of AAAs were defined by the vascular surgeon. In order to adequately compare vascular ultrasound and CTA studies, the interval between the two examinations could not exceed 90 days.

The study was approved by the institutional Research Ethics Committee, and written informed consent was obtained from all patients. Exam interpretation was blinded for test information, even in patients with more than one test pair.

Two different clinics were chosen to perform vascular ultrasound and CTA examinations. Doppler vascular exams were performed by three experienced vascular ultrasonographists certified by the Brazilian Society of Angiology and Vascular Surgery and the Brazilian College of Radiology. The ultrasound equipment used in the present study were Philips EnVisor and Philips HD-11 (Bothell, WA, USA). The vascular ultrasound protocol required 40 minutes to complete and followed the recommendations of Sato et al. ${ }^{12}$. Three radiologists specializing in diagnostic imaging for vascular studies performed 
the CTA examinations. The equipment used in the present study were Elscint Twin Flash / Dual Slice Helical, Toshiba Multislice Aquilion, Siemens 64-channel, and Somatom Definition AS+ / Multislice 128 channels. CTA images were obtained in the axial plane using a multidetector spiral CTA during intravenous injection of iodinated non-ionic contrast. Isotropic multiplanar reconstructions and three-dimensional reconstructions were obtained.

\section{Statistical analysis}

Three aspects were evaluated in the two exams: presence or absence of endoleak, presence of flow in the aortoiliac segment, and maximum AAA diameter. Results were statistically analyzed using three methods: analysis of validity, kappa correlation coefficient, and Pearson's correlation coefficient. The presence or absence of endoleak and the presence of flow in the aortoiliac segment were assessed considering CTA results as the gold standard. Data were entered into $2 \times 2$ tables, and the following validity indices were calculated: sensitivity, specificity, positive predictive value, and negative predictive value. Subsequently, indices of accuracy were calculated for both the presence or absence of endoleak and for patency of the aortoiliac segment. Kappa correlation coefficients were also calculated to assess these two items. Finally, correlation of the largest transverse diameter of the AAA according to Doppler vascular ultrasound and CTA data was calculated using Pearson's correlation coefficient. These results were analyzed using scatter and BlandAltman plots.

\section{RESULTS}

\section{Endoleak assessment}

Among the 50 paired examinations, CTA identified a total of 22 endoleaks (44\%), compared to $12(22 \%)$ with Doppler vascular ultrasound. Paired tests were concordant for the presence or absence of endoleaks in 38 cases (76\%), vs. 12 discordant cases (24\%). Considering CTA as the gold standard for the diagnosis of endoleaks, Doppler ultrasound showed a sensitivity of $54.5 \%$, a specificity of $92.8 \%$, a positive predictive value of $85.7 \%$, a negative predictive value of $92.9 \%$, and an overall accuracy of $76 \%$ (Table 1). Kappa correlation coefficient was 0.49 . Among the 10 false-negative tests, i.e., in which Doppler vascular ultrasound failed to identify endoleaks as per CTA, there were seven cases of type II endoleak and three cases where CTA was unable to unequivocally define endoleak type. Also, among those 10 false-negative cases, we identified three cases with endoleak stabilization, reduction or resolution, four cases with no subsequent followup examination, and three cases in which AAA diameter increased. In the two false-positive cases, i.e., in which Doppler vascular ultrasound identified an endoleak not shown on CTA, intervals of 60 and 80 days had elapsed between the two exams, and Doppler vascular ultrasound, performed first, was unable to define endoleak type. The total number of endoleaks identified by CTA ( $44 \%$ of total sample) were defined as type II in 17 cases, type III in three cases, and unspecified type in four cases (Figures 1 to 4$)$.

\section{Flow in the aortoiliac segment}

Patency rate in the aortoiliac segment was $98 \%$ according to both Doppler vascular ultrasound and CTA. Only one case showed occlusion of the left common and external iliac arteries, which was treated with femoro-femoral bypass. Four cases of hemodynamically significant stenosis (between

Table 1. Sensibility and specificity of Doppler vascular ultrasound for endoleak identification.

\begin{tabular}{lcc}
\hline \multirow{2}{*}{ Doppler vascular } & \multicolumn{2}{c}{ Computed angiotomography } \\
\cline { 2 - 3 } \multicolumn{1}{c}{ ultrasound } & Endoleak absent & Endoleak present \\
\hline Endoleak absent & $26(92.9 \%)$ & $10(45.5 \%)$ \\
Endoleak present & $2(7.3 \%)$ & $12(54.5 \%)$ \\
Total & 28 & 22 \\
\hline
\end{tabular}

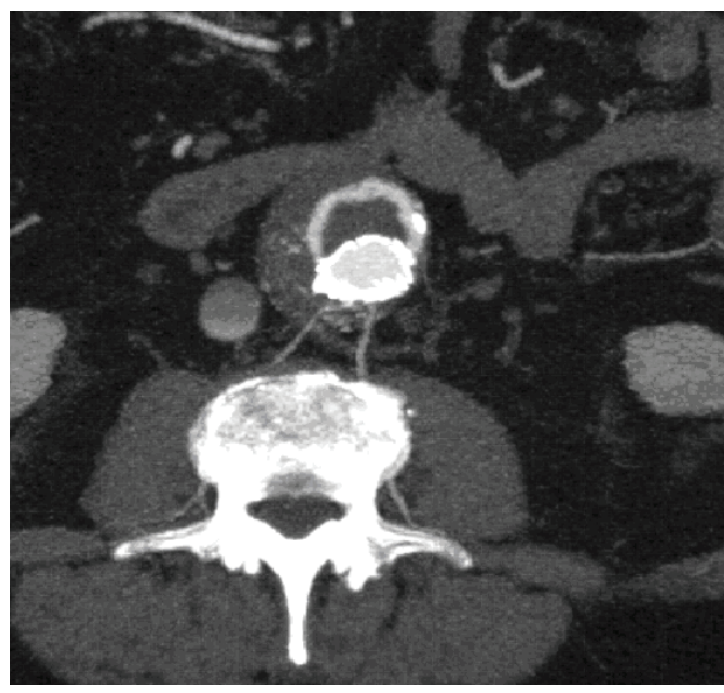

Figure 1. Computed angiotomography obtained in the axial plane showing contrast extravasation into the aneurysm sac and opacification of lumbar arteries at the same level. 


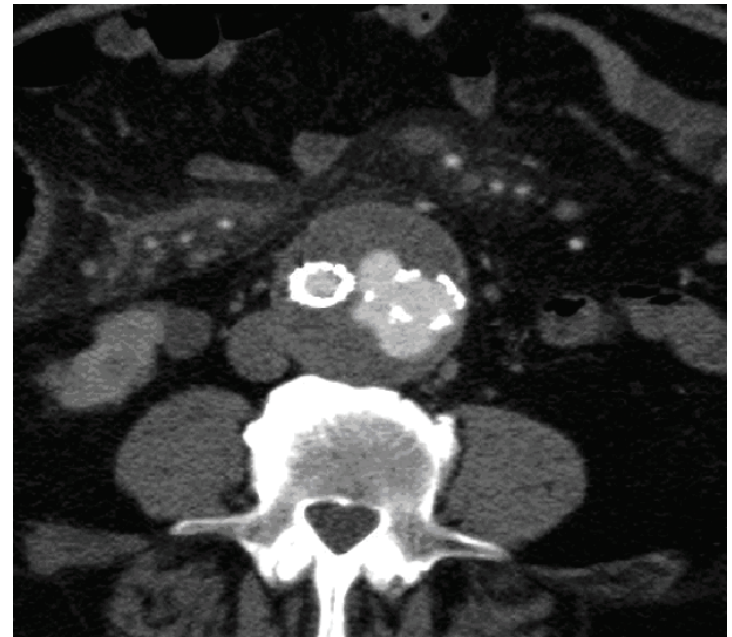

Figure 2. Computed angiotomography obtained in the axial plane showing the presence of contrast externally to the endoprosthesis, associated with deformation of its left branch contour, suggesting a stent defect (type III endoleak).

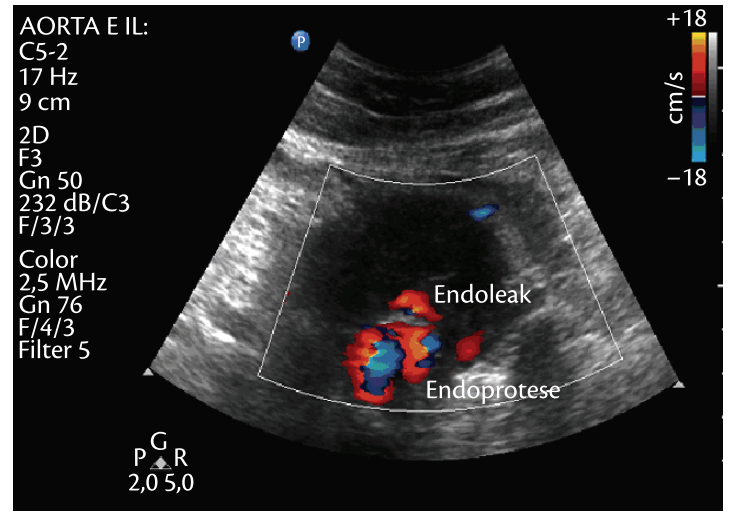

Figure 3. Vascular Doppler ultrasound showing endoleak prior to the stent.

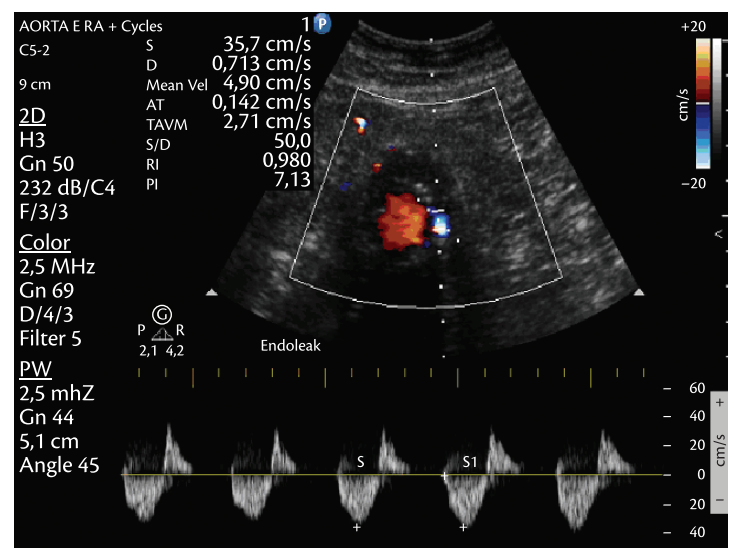

Figure 4. Vascular Doppler ultrasound with spectral analysis of endoleak.
50 and $75 \%$ ) were also identified by both tests. In one case, Doppler vascular ultrasound identified a hemodynamically significant stenosis at the common iliac artery and origin of the left external iliac artery which was not confirmed by CTA. When compared with CTA, Doppler vascular ultrasound showed a sensitivity of $100 \%$, a specificity of $97.8 \%$, a predictive positive value of $80 \%$, a negative predictive value of $97.8 \%$, and an overall accuracy of $98 \%$. Kappa correlation coefficient was 0.88 (Table 2).

\section{Maximum AAA diameter}

Maximum transverse diameters of the aneurysm sac following endovascular AAA repair were $54.5 \pm 12.6 \mathrm{~mm}$ for CTA and $52.5 \pm 13.1 \mathrm{~mm}$ for Doppler vascular ultrasound. In a paired analysis, no significant differences were observed between the two measures (mean difference of $1.98 \mathrm{~mm}$ ). Pearson's correlation coefficient was 0.97 ( $\mathrm{p}<0.001$ ), demonstrating that Doppler vascular ultrasound and CTA yielded similar results (Figures 5 and 6).

\section{DISCUSSION}

This prospective study compared postoperative Doppler vascular ultrasound and CTA findings following endovascular treatment of AAAs in 33 patients, at a total of 50 paired examinations. Data were statistically analyzed assuming an independent character among multiple tests per patient, as previously described by other authors ${ }^{13-15}$.

The goal of postoperative exams in the endovascular treatment of AAAs is to diagnose possible complications, and therefore the test used should have high sensitivity and a high negative predictive value. Following endovascular treatment, angiography has been considered to be the gold standard examination. This study used different models of CTA scanners, however with similar techniques, with acquisition of arterial phase images using high contrast flow followed by late stage images for leak detection with slow flow, suggesting that there were no significant differences between the CTA images acquired using the different devices. With regard to the equipment used for

Table 2. Sensibility and specificity of Doppler vascular ultrasound for stenosis identification.

\begin{tabular}{lcc}
\hline Doppler vascular & \multicolumn{2}{c}{ Computed angiotomography } \\
\cline { 2 - 3 } \multicolumn{1}{c}{ ultrasound } & Patency & Stenosis \\
\hline Patency & $45(97.8 \%)$ & $0(0 \%)$ \\
Stenosis & $1(2.2 \%)$ & $4(100 \%)$ \\
Total & 46 & 4 \\
\hline
\end{tabular}




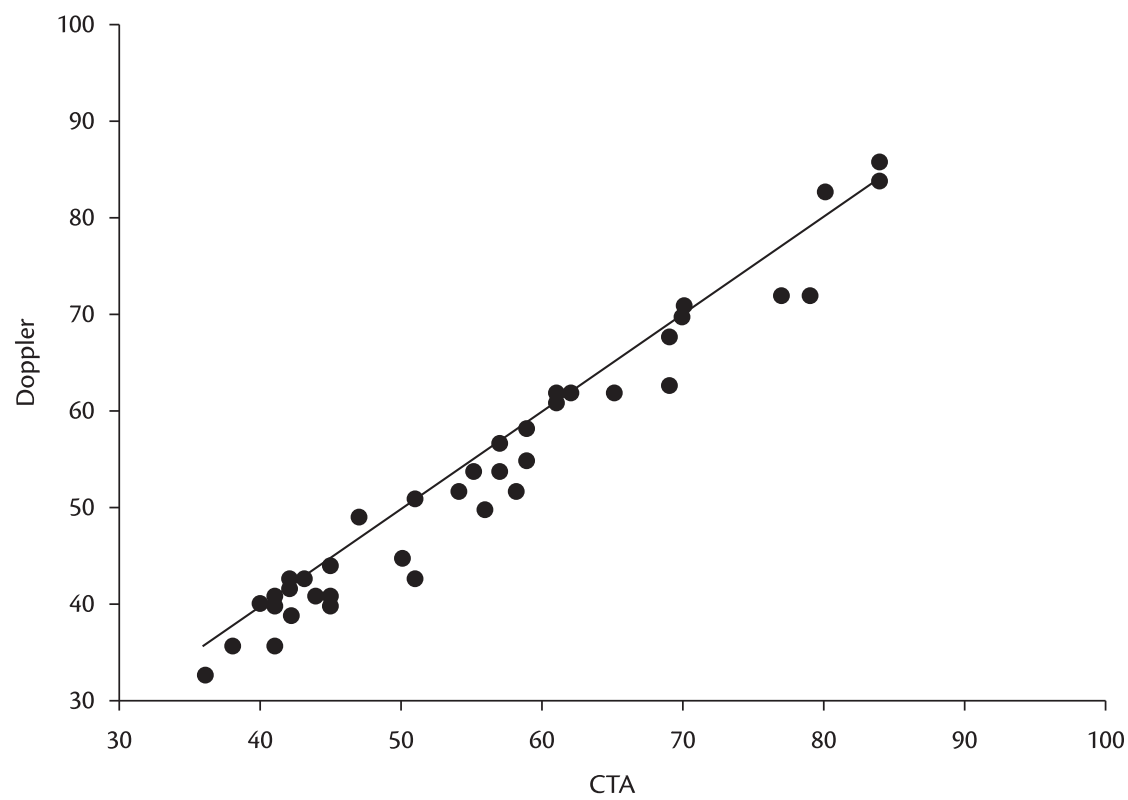

Figure 5. Scatter plot showing correlation between Doppler vascular ultrasound and computed angiotomography findings for AAA diameter.

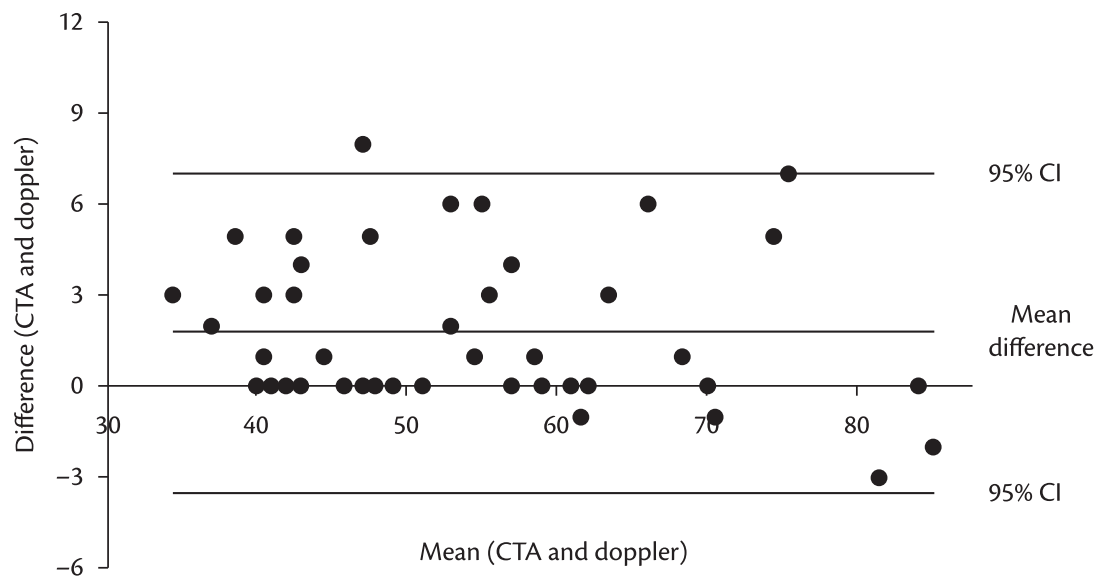

Figure 6. Bland-Altman plot showing limits of agreement and bias estimated for AAA diameter.

Doppler vascular ultrasound, no differences in image acquisition were present that could compromise the results of the analysis.

Studies comparing vascular ultrasound and angiography for the identification of endoleaks have produced mixed results. Sato et al., ${ }^{12}$ in a classic study, and also D'Audiffret et al., ${ }^{14}$ showed that Doppler vascular ultrasound was an excellent test to search for leaks, with sensitivity rates of 97 and $96 \%$, respectively. Excellent results for leak identification were also obtained by Zannetti et al., ${ }^{16}$ with a sensitivity of $91 \%$, and by McLafferty et al., ${ }^{17}$ with a $100 \%$ sensitivity when compared with angiography. Elkoury et al. ${ }^{15}$ in turn, showed poor results for vascular ultrasound in the detection of leaks, with a sensitivity as low as $25 \%$ and a specificity of $89 \%$.

Most studies comparing the two methods have reported moderate sensitivities for the identification of leaks, ranging between 51 and $81 \%$, plus excellent negative predictive values, of 86 to $95 \%^{13,18-20}$. Our study also showed a moderate sensitivity, of $54 \%$, and an excellent negative predictive value, of $92 \%$. These results are very similar to those of Cantisani et al., ${ }^{21}$ who found a $58 \%$ sensitivity and a negative predictive value of $89 \%$ for the detection of leaks. Schmieder et al. ${ }^{22}$ also showed similar results, with a sensitivity of $64 \%$ and a negative predictive value of $93 \%$. 
Even though overall sensitivity rates for leak detection in the aforementioned studies are only moderate, a reduced of sensitivity was observed for type II leaks. Conversely, the sensitivity of Doppler vascular ultrasound for endoleak types I and III is excellent ${ }^{22}$. Aburahma et al. ${ }^{18}$ reported a similar pattern of results, with worst leak detection rates in type II vs. type I - and it should be noted that type II leaks usually follow a benign course. Additionally, in our sample, we consider the two false-positive cases as being truly positive, i.e., assuming that spontaneous leak thrombosis occurred (intervals of 60 and 80 days between Doppler vascular ultrasound and CTA examinations), we would have found an $80 \%$ agreement rate between the two methods; this same interpretation was also followed by McLafferty et al. ${ }^{17}$ Notwithstanding, the long interval allowed between the two examinations, of 90 days, should be considered a limitation of the study.

Regarding the identification of leaks, it should be emphasized that, in this study, Doppler vascular ultrasound did not allow to determine endoleak type. In most cases, classification was made based on CTA findings, but in four of 22 cases (18\%), even CTA was unable to classify the leaks. As previously described by Zannetti et al. ${ }^{16}$ and McLafferty et al., ${ }^{17}$ we believe that Doppler vascular ultrasound is useful to detect a leak and identify its location relative to the graft, but does not unequivocally classify it. Some studies have reported an increased sensitivity for the identification and classification of leaks using vascular ultrasound with contrast $\mathrm{t}^{21,23,24}$. Even though the use of vascular contrast in Doppler ultrasound may help reduce unidentified type II leaks, this approach would increase the number of false-positive tests, as a result of being too sensitive. Moreover, it would increase the cost of examinations, the study time, and would also lose its non-invasive nature, as patients would require an intravenous catheter for injecting the second-generation contrast currently used. In addition, studies so far available have assessed a small number of patients, and have focused primarily on the assessment of the method's effectiveness.

Analysis of the presence of flow in the aortoiliac segment by Doppler vascular ultrasound had a sensitivity of $100 \%$, a specificity of $97 \%$, a positive predictive value of $80 \%$, a negative predictive value of $97 \%$, and an overall accuracy of $98 \%$ in our study, with a kappa correlation of 0.88 . Excellent correlation results between the two methods have also been described by Wolf et al. ${ }^{13}$ and Beeman et al. ${ }^{10}$. When assessing stenosis and/or occlusion of the aortoiliac segment, it is important to mention that arteriography, not CTA, is the gold standard method. A prospective comparative study assessing aortoiliac occlusive disease has reported high levels of validity and correlation ${ }^{25,26}$.

Even though CTA is not the gold standard for the diagnosis of stenosis and/or occlusion, we could justify the relatively low positive predictive value found in our sample by the fact that, in one case, CTA did not confirm the hemodynamically significant stenosis (between 50 and 75\%) present in the common iliac artery and origin of the left external iliac artery. While reviewing this exam, the radiologist suggested the presence of an image artifact that allowed the stenosis to be identified by vascular ultrasound. Beeman et al. ${ }^{10}$ also believe that vascular Doppler ultrasound is more accurate than CTA to identify patency and other problems such as kinking and stenosis. The color flow images associated with waveform analysis (spectral analysis) provide anatomic and hemodynamic data that are not possible to assess by CTA. In their study, vascular ultrasound accurately identified all seven cases of graft patency problems requiring treatment ${ }^{10}$.

Finally, regarding evaluation of the maximum diameter of an AAA, the paired analysis showed no statistically significant differences between measurements obtained with the two methods, plus an excellent Pearson correlation coefficient of 0.97 $(\mathrm{p}<0.001)$. Therefore, Doppler vascular ultrasound in our study measured the diameter of aneurysm sacs as precisely as CTA, and could be safely used to determine indications for an intervention based on aneurysm expansion. These results are very similar to those reported by Wolf et al., ${ }^{13}$ who found a correlation of 0.93 , and Beeman et al. ${ }^{10}$ with a correlation of 0.95 .

Reduction in AAA size has been used as a surrogate marker for successful exclusion and thrombosis of the aneurysm sac and a reduced risk of rupture. Even though, in our study, a very good correlation was found for maximum AAA diameter between the two methods, we agree with Wolf et al. ${ }^{13}$ in that Doppler vascular ultrasound is highly operator-dependent, especially when used to evaluate intracavitary structures such the abdominal aorta. For this reason, comparisons between tests should be conducted in the same vascular ultrasound service. In the present study, no interobserver analysis was performed, which can be considered another limitation.

Despite several comparative studies, to date CTA remains as the gold standard for postoperative 
evaluation of endovascular surgery, especially because of the moderate sensitivity associated with vascular ultrasound in the detection and classification of leaks. The advantages of CTA vs. vascular ultrasound are its reproducibility, the fact that it is less influenced by obesity, and the rapid acquisition of images. Conversely, limitations include the potential risk of carcinogenesis due to repeated exposure to ionizing radiation (an incipient concern among most physicians in the U.S. and probably also in Brazil), the risk of complications associated with the use of iodinated contrast, including allergic reactions and kidney failure, and the high cost of the exam. Doppler vascular ultrasound, in turn, is noninvasive, inexpensive, widely accessible, and, when conducted by experienced doctors and with proper equipment, has shown moderate to good correlation with angiography in the diagnosis of leaks and excellent correlation in the assessment of flow in the aortoiliac segment and in aneurysm sac measurement.

The findings discussed above are similar to those reported by other authors ${ }^{10,12,13,16,17,22,27,28}$ and may suggest the possibility to implement new follow-up protocols after endovascular treatment whenever endoleaks and an increased aneurysm sac are not detected on the first postoperative angiography. In these cases, vascular ultrasound could be considered an alternative method for annual monitoring. For example, in most patients showing absence of leakage and no increase in aneurysm diameter after 30 and 365 days, the recommended follow-up protocol could be vascular ultrasound rather than angiography performed annually thereafter. Conversely, in the small number of patients showing early leakage and an increased risk for complications, more aggressive monitoring, diagnosis, and possible treatment approaches are indicated. In our opinion, in cases showing good outcomes after AAA endovascular treatment as documented by angiography at early follow-up, the alternate use of Doppler vascular ultrasound and CTA could result in lower costs, less exposure to ionizing radiation, and less potential nephrotoxicity due to use of contrasts, without compromising the ultimate goal of treatment, namely, prevention of aneurysm rupture.

\section{CONCLUSIONS}

Considering CTA as the gold standard in the postoperative evaluation of endovascular treatment of AAAs, Doppler vascular ultrasound showed high sensitivity and a moderate correlation for the diagnosis of endoleak, high sensitivity and a good correlation in the evaluation of aortoiliac flow, and a good correlation determining maximum AAA diameter.

\section{REFERENCES}

1. Brito CJ. Aneurismas da aorta abdominal. In: Maffei FHA. Doenças vasculares periféricas. 4. ed. São Paulo: Guanabara Koogan; 2008 p. $1254-1285$.

2. Molnar LJ, Langer B, Serro-Azul J, Wanjgarten M, Cerri GG Lucarelli CL. Prevalência de aneurisma intra-abdominal em idosos. Rev Assoc Med Bras. 1995;41:43-46. PMid:7550413.

3. Barros FS, Pontes SM. Rastreamento do aneurisma da aorta abdominal na população da cidade de Vitória, E.S., Brasil. J Vasc Bras. 2005;4:59-65.

4. Simão ACP, Gonçalves ACA, Paulino $M M$, Oliveira RB, Polli CA, Fratezi AC. Estudo comparativo entre o tratamento endovascular e cirurgia convencional na correção eletiva de aneurisma de aorta abdominal: Revisão bibliográfica. J Vasc Bras. 2009;8:335-342. http://dx.doi.org/10.1590/S1677-54492009000400009

5. Gama AD. Recomendações para o tratamento do aneurisma da aorta abdominal: uma comparação das recomendações de 1992 com as de 2003. J Vasc Bras. 2004;3:38-42.

6. Parodi JC, Palmaz JC, Barone HD. Transfemoral intralumina graft implantation for abdominal aortic aneurysms. Ann Vasc Surg. 1991;5:491-499. PMid:1837729. http://dx.doi.org/10.1007/ BF02015271

7. Puech-Leão P. Correção endoluminal dos aneurismas. In: Maffe FHA. Doenças vasculares periféricas. 4. ed. São Paulo: Guanabara Koogan; 2008. p. 1386-1398.

8. Gorham TJ, Taylor J, Raptis S. Endovascular treatment of abdominal aortic aneurysm. Br J Surg. 2004;91:815-827. PMid:15227687. http://dx.doi.org/10.1002/bjs.4611

9. Brenner DJ, Hall EJ, Phil D. Computed tomography - an increasing source of radiation exposure. N Engl J Med. 2007;357:2277-2284. PMid:18046031. http://dx.doi.org/10.1056/NEJMra072149

10. Beeman BR, Doctor LM, Doerr K, McAfee-Bennett S, Dougherty MJ, Calligaro KD. Duplex ultrasound imaging alone is sufficient for midterm endovascular aneurysm repair surveillance: $A$ cost analysis study and prospective comparison with computed tomography scan. J Vasc Surg. 2009;50:1019-1024. PMid:19656651. http://dx.doi.org/10.1016/j.jvs.2009.06.019

11. Lacerda AFC. O valor do eco color Doppler para o diagnóstico de vazamento no tratamento endovascular do aneurisma da aorta abdominal [dissertação]. Rio de Janeiro: Universidade Federal do Rio de Janeiro; 2003.

12. Sato DT, Goff CD, Gregory RT, et al. Endoleak after aortic stent graft repair: Diagnosis by color duplex ultrasound scan versus computed tomography scan. J Vasc Surg. 1998;28:663-677. http:// dx.doi.org/10.1016/S0741-5214(98)70091-6

13. Wolf YG, Johnson BL, Hill BB, Rubin GD, Fogarty TJ, Zarins CK Duplex ultrasound scanning versus computed tomographic angiography for postoperative evaluation of endovascular abdominal aortic aneurysm repair. J Vasc Surg. 2000;32:1142-1148. PMid:11107086. http://dx.doi.org/10.1067/mva.2000.109210

14. D’Audiffret A, Desgranges P, Kobeiter DH, Becquemin JP. Follow up evaluation of endoluminally treated abdominal aortic aneurysms with duplex ultrasonography: validation with computed tomography. J Vasc Surg. 2001;33:42-50. PMid:11137922. http:// dx.doi.org/10.1067/mva.2001.112215 
15. Elkoury S, Panneton JM, Andrews JC, et al. Computed tomography and ultrasound in follow up of patients after endovascular repair of abdominal aortic aneurysm. Ann Vasc Surg. 2004;18:271-279. PMid:15354627. http://dx.doi.org/10.1007/s10016-004-0034-5

16. Zannetti S, De Rango P, Parente B, et al. Role of duplex scan in endoleak detection after endoluminal abdominal aortic aneurysm repair. Eur J Vasc Endovasc Surg. 2000;19:531-535. http://dx.doi. org/10.1053/ejvs.1999.1033

17. McLafferty RB, McCrary BS, Mattos MA, et al. The use of color flow duplex scan for the detection of endoleaks. J Vasc Surg. 2002;36:100-104. http://dx.doi.org/10.1067/mva.2002.123089

18. Aburahma AF, Welch CA, Mullins BB, Dyer B. Computed tomography versus color duplex ultrasound for surveillance of abdominal aortic stent-grafts. J Endovasc Ther. 2005;12:645-651. http://dx.doi.org/10.1583/05-1575MR.1

19. Raman KG, Missig-Carroll N, Richardson T, Muluk SC, Makaroun MS. Color flow duplex ultrasound scan versus computed tomographic scan in the surveillance of endovascular aneurysm repair. J Vasc Surg. 2003;38:645-651. http://dx.doi.org/10.1016/ S0741-5214(03)00909-1

20. Sun Z. Diagnostic value of color duplex ultrasonography in the follow up of endovascular repair of abdominal aortic aneurysm. J Vasc Interv Radiol. 2006;17:759-764. http://dx.doi.org/10.1097/01. RVI.0000217944.36738.02

21. Cantisani V, Ricci P, Grazhdani H. Prospective comparative analysis of colour-doppler ultrasound, contrast-enhanced ultrasound, computed tomography and magnetic resonance in detecting endoleak after endovascular abdominal aortic aneurysm repair. Eur J Vasc Endovasc Surg. 2011;41:186-192. http://dx.doi. org/10.1016/j.ejvs.2010.10.003

22. Schmieder DC, Stout CL, Stokes GK, Parent FN, Panneton JM. Endoleak after endovascular aneurysm repair: Duplex ultrasound imaging is better than computed tomography at determining the need for intervention. J Vasc Surg. 2009;50:1012-1018. http:// dx.doi.org/10.1016/j.jvs.2009.06.021

23. Henao EA, Hodge MD, Felkai DD, et al. Contrast-enhanced duplex surveillance after endovascular abdominal aortic aneurysm repair: improved efficacy using a continuous infusion technique. J Vasc Surg. 2006;43:259-264. http://dx.doi.org/10.1016/j.jvs.2005.09.045

24. Giannoni MF, Fanelli F, Citone M, Cristina Acconcia M, Speziale F, Gossetti B. Contrast ultrasound imaging: the best method to detect type II endoleak during endovascular aneurysm repair follow up. Interact Cardiovasc Thoracic Surg. 2007;6:359-362. http://dx.doi.org/10.1510/icvts.2006.137265

25. Cumha CLP. Ecocardiografia com contraste. Tem futuro? Arq Bras Cardiol. 2006;87:197-199. http://dx.doi.org/10.1590/ S0066-782X2006001500020
26. Moreira RCR. Estudo comparativo de eco-Doppler com arteriografia na avaliação da doença oclusiva aortoilíaca. J Vasc Bras. 2009;8:3-13. http://dx.doi.org/10.1590/ S1677-54492009000100002

27. Manning BJ, O'Neill SM, Haider SN, Colgan MP, Madhavan P, Moore DJ. Duplex ultrasound in aneurysm surveillance following endovascular aneurysm repair: a comparison with computed tomography aortography. J Vasc Surg. 2009;49:60-65. http:// dx.doi.org/10.1016/j.jvs.2008.07.079

28. Collins JT, Boros MJ, Combs K. Ultrasound surveillance of endovascular aneurysm repair: A safe modality versus computed tomography. Ann Vasc Surg. 2007;21:671-675. http://dx.doi. org/10.1016/j.avsg.2007.07.009

Correspondence Liz Andrea Villela Baroncini Rua Buenos Aires, 764/601 CEP 80250-070 - Curitiba (PR), Brasil Tel./Fax: +55 (41) 3352-2006 E-mail: lizandreabaroncini@hotmail.com

Author's information

GJF PhD. Vascular surgeon and ultrasonographist, Sociedade Brasileira de Angiologia e de Cirurgia Vascular (SBACV). Physician, Vascular Ultrasound Service, Clínica Áurea and Hospital de Clínicas da Universidade Federal do Paraná (UFPR).

LAVB PhD. Cardiologist physician, echocardiographist, and vascular ultrasonographist, Clinica Cendicardio and Clínica Aura. AO Vascular surgeon and ultrasonographist, Sociedade Brasileira de Angiologia e de Cirurgia Vascular (SBACV). Physician, Vascular Ultrasound Service, Clínica Áurea.

EAV Ultrasonographist, Sociedade Brasileira de Angiologia e de Cirurgia Vascular (SBACV). Technical manager, Vascular Ultrasound Service, Clínica Áurea.

MM Vascular surgeon, Sociedade Brasileira de Angiologia e de Cirurgia Vascular (SBACV). Physician, Vascular Surgery Service, Hospital Nossa Senhora das Graças.

JFT Vascular surgeon, Sociedade Brasileira de Angiologia e de Cirurgia Vascular (SBACV). Assistant professor of Angiology and Vascular Surgery at UNIOESTE.

LOMC Radiologist, Clínica DAPI.

JRRT PhD. Associate professor of Vascular Surgery at UFPR. Ful member, Sociedade Brasileira de Angiologia e de Cirurgia Vascular (SBACV) and Colégio Brasileiro de Cirurgiões (CBC).

Author contributions Conception and design: GJF, JRRT Analysis and interpretation: GJF, JFT, JRRT Data collection: GJF, LAVB, LOMC, MM, AO, EAV Writing the article: GJF, LAVB Critical revision of the article: GJF, LAVB, JRRT Final approval of the article*: GJF, JRRT, LAVB Statistical analysis: GJF, JFT Overall responsibility: GJF

*All authors have read and approved the final version submitted to I Vasc Bras. 